\title{
Empirical Identity as an Indicator of Theory Choice
}

\author{
Lei Ma \\ School of Humanities, Southeast University, Nanjing, China \\ Email: yuxuanma@hotmail.com
}

Received 16 September 2014; revised 6 October 2014; accepted 16 October 2014

Academic Editor: Mang Ma, Anhui University, China

Copyright (C 2014 by author and Scientific Research Publishing Inc.

This work is licensed under the Creative Commons Attribution International License (CC BY).

http://creativecommons.org/licenses/by/4.0/

(c) (i) Open Access

\begin{abstract}
There are many theories about theory choice in philosophy of science, but no any indicator of scientific theory has been precisely defined, let alone a united index system. By the example of empirical identity, I shall show that a range of scientific indicators to decide theory choice can be precisely defined by some basic concepts. I think that these indicators can provide us a better description of the principles of philosophy of science. The certain pursuit of theories' empirical identity and novelty leads the cumulative view of scientific progress; under non-cumulative circumstance, it is totally practicable to judge a theory's empirical identity as well as empirical novelty; empirical identity underdetermines the acceptance of a particular theory. It is possible that all the principles of philosophy of science could be explained again through the system of index of theory choice, thus a more rigorous theory of philosophy of science could be established.
\end{abstract}

\section{Keywords}

Empirical Identity, Theory Choice, United Index System, Kuhnian Losses, Underdetermination

\section{The Definition of Empirical Identity}

The aim of this paper is not to present a new tool for analyzing theory choice, but to do a better job motivating how to classify the past achievements and highlight the quantifiable features of scientific indicators. Scientific virtues or indicators have been discussed by many philosophers of science, but there are three problems which should be further discussed. The first problem is that if all scientific indicators could be defined by the same concepts. The second is that if scientific virtues could be measured, appropriated and quantified. The third is that if each of these indicators could describe part of the principles of philosophy of science. If these problems can be answered affirmatively, I believe that a united and statistically significant system of philosophy of science 
can be constructed.

I think that there are three sorts of scientific indexes to depict theory choice, that is, empirical indexes, conceptual indexes and background indexes. These indexes show the theory's problem-solving efficiency, which contains not only a theory's problem-solving quantity and weight, but also "a theory’s problem-solving styles" (i.e., quantified indicators for accepting or pursing a theory). Each sort of indexes includes some single indicators. For instance, empirical indexes include empirical identity, empirical simplicity, empirical unity, empirical novelty, empirical mightiness, and the like; conceptual indexes include conceptual identity, conceptual unity, conceptual novelty, conceptual mightiness, conceptual succinctness, and others; background indexes include background experiment, background technology, background thinking, background psychology, background action, and so on. It is necessary and possible to definite each of these indicators, since a rigorous analytical mechanism is needed to describe theory choice, and a formalized theory of philosophy of science should be constructed.

In this paper, I will give some examples, especially empirical identity, to show that all these indicators may be defined by same conceptions, and that each of these indicators could describe some of principles in philosophy of science. My definition method is to make an unsymmetrical comparison between two theories and to show their merits by basic conceptions "problemor" and "solutionor". I shall not definite empirical identity of scientific theories until "problemor" and "solutionor" and other relevant conceptions have been explained. All single indicators include two aspects of stronger and weaker. What is unsymmetrical comparison between two theories? If each single indicator is regarded as a balance, and if the two theories on both ends of the balance do not weigh the same, then the one theory shows its weaker problem-solving efficiency, and the other shows its stronger problem-solving efficiency. Any theory has two component parts, i.e., the part of problems or questions and the part of solutions to problems or questions. The first part consists of "problemor" which is anything that we feel curious, thirst for understanding and to that we put questions or problems, and the form of posing problems, such as "why", "what", "how" and all. The second part consists of "solutionor" or the join of "solutionors". The conception "solutionor" is generally called all single internal tactics, which are internal reasons to judge the relation between two theories and present static forms of ideology such as definition, hypothesis, law, principle, regulation, method, etc., and all single external tactics, which are external reasons to judge the relation between two theories and present dynamic forms of non-ideology such as the process of observation, experiment, function of technological object, confirmation from scientific communication, support in policy, and that.

When we feel it necessary to raise, in certain form, a problem of an empirical fact or a test implication which could be called "empirical problemor", an empirical problem is generated. A solution to an empirical problem constitutes "empirical solutionor" or the link of some "empirical solutionors”. There are two different kinds of "empirical problemors". I shall call the first an observation-type empirical problemor which is an empirical fact coming from observation or experiment and may constitute an empirical sets by different forms of posing problem. For example, "Why and how an apple falls toward the earth?” Newton's answer is: “There are mutual gravitational force between the apple and the earth”. “An apple falls toward the earth" could be called an observation-type empirical problemor, and Newton's answer constitutes an empirical solutionor. The second could be called a theory-type empirical problemor which is a theory's test implication deduced from theories and, in principle, could be tested by observation and experiment and could in itself bring about an empirical problem sets. Einstein's theory of relativity, for instance, deduced a curved light which could be called a theory-type empirical solutionor. If we examine the matter from solving problems instead of posing problems, all theory-type empirical problemors could be regarded as the lowest level empirical solutionors, since it is the most simple and direct answer to an empirical fact.

According to the above-mentioned definitions and the unsymmetrical relations of theory comparison, the definition of empirical identity is as follows:

By comparison between theory $T_{1}$ at time $\tau$ and theory $T_{2}$ at time $\tau^{\prime}$, we say that $T_{1}$ 's empirical identity decreases (noted by $I T_{1} \tau \downarrow$ ) and $T_{2}$ 's empirical identity increases (noted by $I T_{2} \tau^{\prime} \downarrow$ ), if and only if , at time $\tau, m$ sorts of different theory-type empirical problemors, $w$, that tally with observation-type empirical problemors (noted by 2 ), can be deduced from $T_{1}$ 's empirical solutionors $j$ (noted by $T_{1} \tau\left(j \rightarrow(2 w)^{m}\right)$; at time $\tau^{\prime}, n$ sorts of different theory-type empirical problemors that tally with observation-type empirical problemors, can be deduced from $T_{2}$ 's empirical solutionors $j$ (noted by $T_{2} \tau^{\prime}\left(j \rightarrow(2 w)^{n}\right)$; and $n>m \geq 0$. Here, "tally with" means "with a tolerance of less than the fixed error". Time $\tau$ can be or can not be equal to time $\tau^{\prime}$.

The definition may be stated in symbols as follows: 


$$
I T_{1} \tau \downarrow \wedge I T_{2} \tau^{\prime} \uparrow \leftarrow T_{1} \tau\left(j \rightarrow(2 w)^{m}\right) \wedge T_{2} \tau^{\prime}\left(j \rightarrow(2 w)^{n}\right) \wedge(n>m \geq 0)
$$

\section{Cumulative and Non-Cumulative Empirical Progress}

The cumulative idea of scientific progress reflects, in empirical aspect, certain effort both to pursue a theory's empirical identity and also to pursue a theory's novelty ${ }^{1}$. Collingwood writes: "Progress in science would consist in the supersession of one theory by another which served both to explain all that the first theory explained, and also to explain...'phenomena' which the first ought to have explained but could not...” (Collingwood, 1956: p. 332). Popper also points out: "A new theory, however revolutionary, must always be able to explain fully the success of its predecessor. In all those cases in which its predecessor was successful, it must yield results at least as good..." (Popper, 1975: p. 83). Lakatos' narration is more well-organized, he demands that a series of theories, $T_{1}, T_{2}, T_{n}$, must meet the following characteristics, and hence constitutes a consistently progressive theoretical problemshift:

(A) $T_{n}$ has excess empirical content over $T_{n-1}$ : that is, it predicts novel facts, that is, facts improbable in the light of, or even forbidden, by $T_{n-1}$;

(B) $T_{n}$ explains $T_{n-1}$, that is, all the unrefuted content of $T_{n-1}$ is included (within the limits of observational error) in the content of $T_{n}$;

(C) Some of the excess content of $T_{n}$ is corroborated (cf. Lakatos, 1970: p. 116).

Above-mentioned three progressive characteristics can at least be changed into conditions as follows:

(A') More novel theory-type empirical problemors can be deduced from $T_{n}$ at $\tau^{\prime}$ than from $T_{n-1}$ at $\tau$;

(B') All theory-type empirical problemors tallying with observation-type empirical problemors, which can be deduced from $T_{n-1}$ at $\tau$, can also be deduced from $T_{n}$ at $\tau^{\prime}$;

(C') Some theory-type empirical problemors tallying with observation-type empirical problemors, which can be deduced from $T_{n}$ at $\tau^{\prime}$, can not be deduced from $T_{n-1}$ at $\tau$.

Condition ( $\mathrm{A}^{\prime}$ ) directly expresses the pursuit of a theory's conceptual novelty, and expresses the pursuit of a theory's empirical novelty together with condition $\left(\mathrm{C}^{\prime}\right)$. From conditions $\left(\mathrm{B}^{\prime}\right)$ and $\left(\mathrm{C}^{\prime}\right)$, we can draw that more theory-type empirical problemors tallying with observation-type empirical problemors can be deduced from $T_{n}$ at $\tau^{\prime}$ than from $T_{n-1}$ at $\tau$. Consequently, conditions ( $\left.\mathrm{B}^{\prime}\right)$ and $\left(\mathrm{C}^{\prime}\right)$ co-expresses the pursuit of a theory's empirical identity. The three conditions which have accumulated characteristics represents, from concert force point of view, certain progress pattern in science, and represents, as for empirical identity, a sort of pattern to

${ }^{1}$ I define empirical novelty as follows: By comparison between theory $T_{1}$ at time $\tau$ and theory $T_{2}$ at time $\tau^{\prime}$, we say that $T_{1}$ 's empirical novelty decreases (noted by $E T_{1} \tau \downarrow$ ) and $T_{2}$ 's empirical novelty increases (noted by $E T_{2} \tau^{\prime} \uparrow$ ), if and only if, at $\tau$, $m$ sorts of different novel (noted by $\odot$ ) theory-type empirical problemors, $w$, that tally with observation-type empirical problemors (noted by $2 @ w$ ), can be deduced from $T_{1}$ 's empirical solutionors $j$ (noted by $T_{1} \tau\left(j \rightarrow(2 \odot w)^{m}\right)$ ); and at $\tau^{\prime}, n$ sorts of different novel theory-type empirical problemors, $w$, that tally with observation-type empirical problemors can be deduced from $T_{2}$ 's empirical solutionors $j$ (noted by $\left.T_{2} \tau^{\prime}(j \rightarrow(2 \odot w))^{n}\right)$; and $n>m \geq 0$. Here, "tally with" means "with a tolerance of less than the fixed error". Time $\tau$ can be or can not be equal to time $\tau^{\prime}$.

The definition may be stated in symbols as follows:

$$
E T_{1} \tau \downarrow \wedge E T_{2} \tau^{\prime} \uparrow \longleftrightarrow T_{1} \tau\left(j \rightarrow(2 \odot w)^{m}\right) \wedge T_{2} \tau^{\prime}\left(j \rightarrow(2 \odot w)^{n}\right) \wedge(n>m \geq 0)
$$

For an articulation of this indicator, see especially Ma Lei, 2006, pp. 103-110.

The definition of conceptual novelty is as follows:

By comparison between theory $T_{1}$ at time $\tau$ and theory $T_{2}$ at tine $\tau^{\prime}$, we say that $T_{1}$ 's conceptual novelty decreases (noted by $\mathrm{e} T_{1} \tau \downarrow$ ) and $T_{2}$ 's conceptual novelty increases (noted by $\mathrm{e} T_{2} \tau^{\prime} \uparrow$ ), if and only if, at $\tau, m$ sorts of different novel (noted by (C) solutionors, $j$, can be deduced from $T_{1}$ 's solutionors $j$ (noted by $T_{1} \tau\left(j \rightarrow \subseteq j^{m}\right)$ ); and at $\tau^{\prime}, n$ sorts of different novel solutionors can be deduced from $T_{2}$ 's empirical solutionors (noted by $T_{2} \tau^{\prime}\left(j \rightarrow \odot j^{n}\right)$; and $n>m \geq 0$. Here, "tally with" means "with a tolerance of less than the fixed error". Time $\tau$ can be or can not be equal to time $\tau^{\prime}$.

The definition may be symbolized as follows:

$$
\mathrm{e} T_{1} \tau \downarrow \wedge \mathrm{e} T_{2} \tau^{\prime} \uparrow \leftarrow T_{1} \tau\left(j \rightarrow \subseteq j^{m}\right) \wedge T_{2} \tau^{\prime}\left(j \rightarrow \subseteq j^{n}\right) \wedge(n>m \geq 0)
$$

For an articulation of this indicator, see especially Ma Lei (2006), pp. 103-110. 
pursue empirical identity. Imaging that there is a magic box, $B$, which can not be opened, in which there are some balls different both in colour and in quantity, and as time goes on, the colour and the quantity may be changed. The conceptual novelty of $T_{2}$ at $\tau^{\prime}$ is stronger than theory $T_{1}$ at $\tau$, if, one black ball in $B$ can be deduced from theory $T_{1}$ at $\tau$, but both one black ball and one white ball in B can be deduced from $T_{2}$ at $\tau^{\prime}$. Assuming that, as a result of experimental test, the deductive results of both theory $T_{1}$ at $\tau$ and theory $T_{2}$ at $\tau^{\prime}$ (theory-type empirical problemors) tally with facts (observation-type empirical problemors), then theory $T_{2}$ at $\tau^{\prime}$ is stronger than theory $T_{1}$ at $\tau$ not only in empirical novelty but also in empirical identity. Logical empiricists, however, make a mistake to regard the possible model of progress as an inevitable model of progress, which was criticized by some historians and philosophers of science. As Kuhn put it, there are usually problem losses as well as problem gains associated with the replacement of any older theory by a newer one, i.e., a new theory will lose partial explanatory power when it gains certain new explanatory power (Kuhn, 1962: p. 169). Feyerabend even complained that Lakatos' "progressive problemshift” is a Utopia in science. When theory $T_{1}$ is superseded by theory $T_{2}$, the common case is as follows:

(A) Theory, $T_{2}$, explains theory $T_{1}$ ' partial but not all success.

(B)Theory, $T_{2}$, explains additional predictions that $T_{1}$ can not explain.

This "Kuhnian losses" phenomenon which discovered by Kuhn and Feyerabend is common in science, and becomes a powerful evidence to deny the accumulated view of progress. However, we should avoid thinking in terms of absolutes. It is wrong to repudiate totally accumulated characteristics which may be emerged at certain period of time. Feyerabend, however, has recognized that Lakatos' critical standards have practical force only if they are combined with a time limit (what looks like a degenerating problem shift may be the beginning of a much longer period of advance) (Feyerabend, 1970: p. 215).

Is a new theory with the emergence of "Kuhnian losses" progressive? L. Laudan once gave a vivid historical case, namely, the shift in geological problems early in the nineteenth century, to explain that the progress is possible even if "Kuhnian losses" emerges in a new theory. Prior to Hutton, Cuvier and Lyell, geologists had been interested in some empirical problems to which solutions had been offered, among them: how deposits get consolidated into rocks; how the earth slowly acquired its present form; when and where the various animals and plants originated; how the earth retains its heat; and so on. Yet after 1830, particularly with the emergence of stratigraphy, many of the problems mentioned above were no longer follower with interest by geology, and it does not mean that geology did not make any progress between 1830 and about 1900 for the fact that geological theories after Cuvier and Lyell successfully (addressed themselves to) a very different range of empirical problems, including those of bio-geography, stratigraphy, climate, erosion, and land-sea distribution. A further study would show that the precision and range of empirical problems that could be solved by mid-nineteenth century geology (as well as the acuteness of the conceptual and anomalous problems generated) compared favorably to the overall problem-solving success which late eighteenth-century geological theories could claim for themselves. Laudan writes: "Knowledge of the relative weight or the relative number of problems can allow us to specify those circumstances under which the growth of knowledge can be progressive even when we lose the capacity to solve certain problems” (Laudan, 1977: p. 150). Thus Laudan points out a non-logicism normative stand of the non-cumulative progress, that is, under the situation of overlap or separation of problem sets of any theory and its successor, whether a new theory is progressive or not can be analysed or judged by the relative weight or the relative number of problems. However, Laudan doesn't pay more attention to appropriated and quantified aspects of theory comparison. "The relative weight or the relative number of problems" can not reflect the rich indicators of science, which can be defined by the solutionors and problemors. For example, empirical simplicity is decided by the proportion of problemors to solutionors of a theory. If a theory's most conclusions or solutionors that have been verified deduce from its least assumptions or problemors, we say the theory gain its maximum empirical simplicity. This kind of quantified characters of scientific theory can not be showed in Laudan's theory.

Under non-cumulative circumstances, it is totally practical both to specify a theory's empirical identity and to specify a theory's empirical novelty. From the progressive condition of empirical identity, the demand that more theory-type empirical problemors tallying with observation-type empirical problemors should be deduced from $T_{2}$ at $\tau^{\prime}$ than from $T_{1}$ at $\tau$, does not mean that there must be inclusive relation between the theory-type empirical problemors tallying with observation-type empirical problemors from $T_{1}$ at $\tau$ and those from $T_{2}$ at $\tau^{\prime}$, i.e., between $T_{1} \tau(2 w)$ and $T_{2} \tau^{\prime}(2 w)$. They may overlap and separate. Assuming that one black ball and one white ball in magic box, $B$, can only be deduced from theory $T_{1}$ at $\tau$, and one black ball, one red ball, one blue ball in the same box can be deduced from theory $T_{2}$ at $\tau^{\prime}$, and all the results were tested and verified 
through observation and experiment, then, there is a overlapping relation between the two theories' theory-type empirical problemors that tally with observation-type ones. Assuming that only one black ball in magic box, $B$, can only be deduced from theory $T_{1}$ at $\tau$, and one white ball, one red ball in the same box can only be deduced from theory $T_{2}$ at $\tau^{\prime}$, and all the results were tested and verified through observation and experiment, then, there is a separating relation between the two theories' theory-type empirical problemors that tally with observation-type ones. Under the two kinds of conditions, the empirical identity of theory $T_{2}$ at $\tau^{\prime}$ is in a relative increasing state of affairs. Empirical novelty has similar cases. It is important to note that, under circumstance of kuhnian losses, both a theory's empirical identity and empirical novelty may be retrogressive (i.e., may be in a relative weaker state of affairs), and a theory's comprehensive should also be analysed by specific circumstances. In addition, the theories used to compare could be either from the same domain or from different domains, and could be both synchronic and diachronic.

\section{The Underdetermination of Empirical Identity}

If theory $T_{2}$ explains more facts than $T_{1}$, namely, the quantity of sorts of theory-type empirical problemors tallying with observation-type ones deduced from $T_{2}$ exceed that of from $T_{1}$, then, under this circumstance, to abandon theory $T_{1}$ can not be abundantly decided, for lack of abundant reasons.

Firstly, the starting point of a new theory is often confined to certain narrow domain, so the quantity of empirical problems solved by the new theory may be smaller than an old theory. With further evolvement of the new theory, however, it is entirely possible that the developed new theory could solve more empirical problems than the old theory. At the outset, the theory of Copernicus can not explain more phenomena than the theory of Ptolomy. The opposition to Copernicus was from three famous arguments, namely, there is no stellar parallax; a body thrown upward falls vertically to earth; the objects on the ground is in a state of rest. They asked: As the Earth moves from one place to the opposite place in the same orbit, but why can not the parallax be watched? If the Earth revolves on its axis, a body thrown upward would fall to the west of its point of projection, but why does the body return to its original point? If the Earth spun, loose objects would fly away from the ground, and the Earth itself would fly to pieces, but why do not the phenomena emerge? The Corpernican system was advanced late by Galileo who refuted the three arguments. To counter the first argument, Galileo pointed out that the distance from the star to the Earth is at least ten thousands times as much than that from the Sun to the Earth, because the starts is too far from the Earth, the parallax can not be perceived. That doesn't mean there is no paradox. In the light of the second argument, Galileo refuted it by the law of inertia. Before Galileo, it was assumed that every motion required a continual force to maintain it. But Galileo found that it is not motion, but the creation or destruction of motion, or a change in its direction, that requires external force. When matter is endowed with inertia, a body thrown upward and the air share the rotation of the Earth, a falling body would return to its original place. In accordance with the third argument, Galileo said that the rotation of the Earth is slow, and centrifugal force is far smaller than gravitational force, so objects would be independent of the rotation of the Earth, and still stay where they are. Galileo not only refuted the opposition to Corpernicus, but also explained briefly, by the rotation of the Earth, the phenomena which the theory of Ptolomy can not explain, such as the halt and retrograde motion of the planets, tide and trade wind on the Earth, and so on.

Secondly, if a theory's empirical novelty is strong enough, there would have a vast space for the growth of the theory's empirical identity, but the solution to the theory's weaker empirical identity can not be worked out from it. Besides revising and perfecting a theory to dispel the weaker empirical identity, experiment designs and experiment conditions are also very important, namely, the background experiment ${ }^{2}$ should be strengthen. Howev-

\footnotetext{
${ }^{2}$ Background experiment is one of background index of a theory. The definition of it is as follows:

By comparison between theory $T_{1}$ at time $\tau$ and theory $T_{2}$ at time $\tau^{\prime}$, we say that $T_{1}$ 's background experiment decreases (noted by $x T_{1} \tau \downarrow$ ) and $T_{2}$ 's background experiment increases (noted by $x T_{2} \tau^{\prime} \uparrow$ ), if and only if, the aggregative evaluation index number $m$ of $T_{1}$ 's experimental solutionors $j$ at $\tau$ (noted by $m\left(T_{1} \tau x j\right)$ ) is less than the aggregative evaluation index number $n$ of $T_{2}$ 's experimental solutionor $j$ at $\tau^{\prime}$ (noted by $n\left(T_{2} \tau^{\prime} x j\right)$ ). Time $\tau$ can be or can not be equal to time $\tau^{\prime}$.
}

The definition may be symbolized as follows:

$$
x T_{1} \tau \downarrow \wedge x T_{2} \tau^{\prime} \uparrow \longleftrightarrow m\left(T_{1} \tau x j\right)<n\left(T_{2} \tau^{\prime} x j\right)
$$

The aggregative evaluation index of experiment solutionors include experiment design, experiment operation, experiment apparatus, experiment results, experiment analysis, and so on, which should be studied detail by detail. For an account of this indicator, see Ma Lei (2006), pp. 285-292. 
er, a theory's novel prediction may take long before being tested and verified by experiments. As a result of the essential invention of astronomical instrument and method, an observation of the parallax of a fixed star, which was predicted by Corpernicus early in the sixteenth century, was made by Henderson at the Cape of Good Hope in 1832, and accurate measurements by F. W. Bessel and by Struve followed in 1838. In the beginning of the twenty century, Einstein, by the general relativity, proposed a quadrupole formula of gravitational wave, by which the existence of gravitational wave is quantitatively predicted. Although gravitational wave has not been discovered, scientists have been trying every means to observe it. In order to survey gravitational wave, a sensitive gravitational antenna needs designs to overcome strong background interference, acoustic sounder, weber bar (name after Joseph Weber, whose pioneering work in 1960s are still inspiring present scientists), monocrystal, electromagnetic detector such as laser interferometer, etc., need to be designed to survey the frequency rage from $100 \mathrm{~Hz}$ to $10 \mathrm{kHz}$. To employ space probe to find gravitational wave (range from 10 - 2 to $10-4 \mathrm{~Hz}$ ) by Doppler's tracking method is take into consideration. At the present time, experts of experiment relativity hunger for employing pulsar to observe directly gravitational wave.

Thirdly, the decreasing trend of empirical mightiness ${ }^{3}$ and empirical distinctness ${ }^{4}$ is certain to weaken empirical identity at one stage, but empirical mightiness and empirical distinctness may increase in another stage and enhance empirical identity. The inconsistency between a theory's deductions and experimental data leads to the drop tread of empirical mightiness and empirical distinctness, and thus reduce empirical identity. Any experiment, however, has a direct bearing on designed level, auxiliary theories, and explanation, therefore so-called "falsification" of an experiment at certain time may not only arouse many controversy within the period of time, but also be proved to be inadequate, even be placed by other "verified" experiments. In 1906, W. Kaufmann gave the relationship of velocity and mass by the experiment that the cathode rays could be deflected by an electric field as well as by a magnetic field, he claimed that the relationship is not in agreement with Einstein's spe${ }^{3}$ Empirical mightiness is one of empirical indices of a theory. I define it as follows:

By comparison between theory $T_{1}$ at $\tau$ and theory $T_{2}$ at $\tau^{\prime}$, we say that $T_{1}$ 's empirical mightiness decreases (noted by $M T_{1} \tau \downarrow$ ) and $T_{2}$ 's empirical mightiness increases (noted by $M T_{2} \tau^{\prime} \uparrow$ ), if and only if, at $\tau, m$ sorts of different theory-type empirical problemors $w$, that do not tally with observation-type empirical problemors (noted by $\neg 2$ ), can be deduced from $T_{1}$ 's nucleus solutionors $j_{1}$ together with other ones $j_{2}$ (noted by $T_{1} \tau\left(\left(j_{1} \wedge j_{2}\right) \rightarrow(\neg 2 w)^{m}\right)$; and at $\tau^{\prime}, n$ sorts of different theory-type empirical problemors, $w$, that do not tally with observation-type empirical problemors, can be deduced from $T_{2}$ 's nucleus solutionors $j_{1}$ together with other ones $j_{2}$ (noted by $T_{2} \tau^{\prime}\left(\left(j_{1} \wedge j_{2}\right) \rightarrow(\neg 2 w)^{n}\right)$; and let $m>n$ by making $j_{1}$ invariable and $j_{2}$ variable (noted by $\left(j_{1} \wedge \Delta j_{2}\right) \rightarrow m>n$, where, for every $m$ and $n, m, n \geq 0)$. Here, “ $\Delta$ " for "variable" that means "be modified, be suppressed, be added, or be replaced by one or more new solutionors”); ‘do not tally with’ means "exceed the fixed error”; "nucleus solutionors” are those which are directly developed by certain key concept, i.e., a set of theoretical statements on the key concept; "other solutionors" include hypothesis, initial condition, boundary condition. Time $\tau$ can be or can not be equal to time $\tau^{\prime}$.

The definition may be symbolized as follows:

$$
M T_{1} \tau \downarrow \wedge M T_{2} \tau^{\prime} \uparrow \longleftrightarrow T_{1} \tau\left(\left(j_{1} \wedge j_{2}\right) \rightarrow(\neg 2 w)^{n}\right) \wedge T_{2} \tau^{\prime}\left(\left(j_{1} \wedge j_{2}\right) \rightarrow(\neg 2 w)^{n}\right) \wedge\left(\left(j_{1} \wedge \Delta j_{2}\right) \rightarrow m>n\right) .
$$

For a detail discussion of this index, see especially Ma Lei (2006), pp. 110-116.

${ }^{4}$ Empirical distinctness is one of empirical indices of a theory. The definition of the index is as follows:

By comparison between theory $T_{1}$ at $\tau$ and theory $T_{2}$ at $\tau^{\prime}$, we say that $T_{1}$ 's empirical distinctness decreases (noted by $D T_{1} \tau \downarrow$ ) and $T_{2}$ 's empirical distinctness increases (noted by $D T_{2} \tau^{\prime} \uparrow$ ), if and only if, at $\tau, m$ sorts of different theory-type empirical problemors, $w$, that do not tally with observation-type empirical problemors (noted by $\neg 2$ ), can be deduced from $T_{1}$ 's nucleus solutionors $j_{1}$ together with other ones $j_{2}$ (noted by $T_{1} \tau\left(\left(j_{1} \wedge j_{2}\right) \rightarrow(\neg 2 w)^{m}\right)$ ); and at $\tau^{\prime}, n$ sorts of different theory-type empirical problemors, $w$, that do not tally with observation-type empirical problemors, can be deduced from $T_{2}$ 's nucleus solutionors $j_{1}$ together with other ones $j_{2}$ (noted by $T_{2} \tau^{\prime}\left(\left(j_{1} \wedge j_{2}\right) \rightarrow(\neg 2 w)^{n}\right)$; and let $m>n$ by making $j_{1}$ variable and $j_{2}$ invariable (noted by $\left(\Delta j_{1} \wedge j_{2}\right) \rightarrow m>n$, where, for every $m$ and $\left.n, m, n \geq 0\right)$. Here, " $\Delta$ ” for "variable" that means "be modified, be suppressed, be added, or be replaced by one or more new solutionors"); “do not tally with” means "exceed the fixed error”; “nucleus solutionors” are those which are directly developed by certain key concept, i.e., a set of theoretical statements on the key concept; "other solutionors" include auxiliary hypothesis, initial condition, boundary condition. Time $\tau$ can be or can not be equal to time $\tau^{\prime}$.

The definition may be symbolized as follows:

$$
D T_{1} \tau \downarrow \wedge D T_{2} \tau^{\prime} \uparrow \leftarrow T_{1} \tau\left(\left(j_{1} \wedge j_{2}\right) \rightarrow(\neg 2 w)^{m}\right) \wedge T_{2} \tau^{\prime}\left(\left(j_{1} \wedge j_{2}\right) \rightarrow(\neg 2 w)^{n}\right) \wedge\left(\left(j_{1} \wedge \Delta j_{2}\right) \rightarrow m>n\right)
$$

For a detail study of this indicator, see especially Ma Lei (2006), pp. 117-128. 
cial relativity, and further claimed that the measured value does not agree with Lorentz-Einstein hypothesis, but agree with Abraham-Bucherer equation. Kaufmann's experimental results is unfavorable to Lorentz-Einstein hypothesis, Lorentz was somewhat disappointed and wavered between two choices, while Einstein's stand is firm and unshakable. Einstein's confidence does not come from his doubt of Kaufmann's experiment, he commended that Kaufmann's work to define the relation between electric and magnetic deflection of $\beta$ rays is careful and respectable. Although Einstein confirmed that the curve from Abraham-Bucherer's theory tallies more with experimental results than with the curve from relativity, he believed that Abraham-Bucherer's theory has little possibility of success, because their basic assumption about moving electron mass can not be proved by a theoretical system which contains more wide-ranging and complicated phenomena, that is, can not be proved by a theory that has stronger empirical identity and empirical unity ${ }^{5}$. Unlike Einstein, W. Wien doubts the reliability of Kaufmann's experiment, he, early in 1912, wrote a letter to Nobel committee in which he denied that the experiment of cathode rays and $\beta$ rays has decisive proving force, for the experiment is too delicate to guarantee cancelling all errors. The experiment to support relativism was finished in 1914-1916.

Finally, in the indicator system, even if a theory's single indicator is in the state of decrease, scientists should not lose their confidence in the theory, because the theory's other indicators may have an outstanding advantage. Scientists have reasons to believe that as long as a theory's single or partial indicators are stronger, they will, sooner or later, promote the development of other indicators, and thus the complex index will surpass its rivals. Judged by the history of science, Ptolemy's geocentric theory, which has considerable practical value, had been dominating the Western astronomy for 1500 years. Some scientific historians and philosophers of science argue that almost no evidence show that Corpernican system is better than Ptolomaic system in empirical identity and empirical accurate, it may be empirical simplicity ${ }^{6}$ that appeals a lot of scientists. Someone even denies that the acceptance of Corpernican theory comes from its practical purposes, namely, the pursuit of the system comes from its explanation of phenomena, accurate prediction and simplicity. Kuhn points out that Corpernicus's argument does not appeal to the judgment from utility, but only to their aesthetic judgment, i.e., to their perception of mathematical harmony (Kuhn, 1957: p. 81). James W. McAllister simply asserts that the acceptance of Corpernican theory is not determined by empirical factors, but chiefly by esthetic factors. He argues that Corpernican mathematical theory of astronomy is more strictly accord with Aristotelian physicism than Ptolomaic theory ${ }^{5}$ Empirical unity is one of empirical indicators of a theory. I define the index as follows:

By comparison between theory $T_{1}$ at $\tau$ and theory $T_{2}$ at $\tau^{\prime}$, we say that $T_{1}$ 's empirical unity decreases (noted by $U T_{1} \tau \downarrow$ ) and $T_{2}$ 's empirical unity increases (noted by $U T_{2} \tau^{\prime} \uparrow$ ), if and only if, at $\tau, m$ sorts of heterogeneous empirical ranges (noted by $W^{m}$ ) are involved by theory-type empirical problemors, $w$, that tally with observation-type empirical problemors (noted by $2 w \rightarrow W^{m}$, where “ $2 w$ for "tally with observation-type empirical problemors”) and that can be deduced from $T_{1}$ 's empirical solutionors $j$ (noted by $j \rightarrow 2 w$ ); and at $\tau^{\prime}, n$ sorts of heterogeneous empirical ranges (noted by $W^{n}$ ) are involved by theory-type empirical problemors, $w$, that tally with observation-type empirical problemors (noted by $2 w \rightarrow W^{n}$, where “ $2 w$ ” for "tally with observation-type empirical problemors”) and that can be deduced from $T_{2}$ 's empirical solutionors $j$ (noted by $j \rightarrow 2 w$ ); and $n>m \geq 0$. Here, "heterogeneous" means differences in substance, property, structure, or level. Time $\tau$ can be or can not be equal to time $\tau^{\prime}$.

The definition may be symbolized as follows:

$$
U T_{1} \tau \downarrow \wedge E T_{2} \tau^{\prime} \uparrow \longleftrightarrow T_{1} \tau\left((j \rightarrow z w) \wedge\left(z w \rightarrow W^{m}\right)\right) \wedge T_{2} \tau^{\prime}\left((j \rightarrow z w) \wedge\left(2 w \rightarrow W^{n}\right)\right) \wedge(n>m \geq 0)
$$

For an articulation of this index, see especially Ma Lei (2006), pp. 179-188.

${ }^{6}$ Empirical succinctness is one of empirical indicators of a theory. I define empirical novelty as follows:

By comparison between theory $T_{1}$ at $\tau$ and theory $T_{2}$ at $\tau^{\prime}$, we say that $T_{1}$ 's empirical succinctness decreases (noted by $S T_{1} \tau \downarrow$ ) and $T_{2}$ 's empirical succinctness increases (noted by $S T_{2} \tau^{\prime} \uparrow$ ), if and only if, at $\tau, m$ sorts of different theory-type empirical solutionors $j$ (noted by $j^{m}$ ) are established and applied by theory $T_{1}$, and $u$ sorts of different theory-type empirical problemors, $w$, that tally with observation-type empirical problemors (noted by $2 w^{u}$ ) can be deduced from $T_{1}$; and at $\tau^{\prime}, n$ sorts of different theory-type empirical solutionors (noted by $j^{n}$ ) are established and applied by theory $T_{2}$, and $v$ sorts of different theory-type empirical problemors, $w$, that tally with observation-type empirical problemors (noted by $2 w^{v}$ ) can be deduced from $T_{2}$ and the specific value of $m \quad$ to is greater than the specific value of $n$ to $v$. Here, for every $m, n, u$ and $v, m, n 、 u 、 v \geq 1$. Time $\tau$ can be or can not be equal to time $\tau^{\prime}$.

The definition may be symbolized as follows:

$$
S T_{1} \tau \downarrow \wedge S T_{2} \tau^{\prime} \uparrow \leftarrow T_{1} \tau\left(j^{m} \rightarrow c w^{u}\right) \wedge T_{2} \tau^{\prime}\left(j^{n} \rightarrow 2 w^{v}\right) \wedge(m / u>n / v)
$$

For a detail study of this indicator, see Ma Lei (2006), pp. 162-175. 
(McAllister, 1996: pp. 163-181). It is arbitrary that esthetic factors are confined within the limits of category aspects and considered without empirical and background factors. But their arguments show that the initial acceptance of Corpernican theory is deeply influenced by its stronger conceptual indexes. At the beginning of founding relativity theory, the theory's stronger succinctness and background thinking ${ }^{7}$ play an important role in compensating its unfavorable condition of its weaker empirical identity. While Kaufmann's experiment is adverse to relativity theory, M. Plank stood firmly by Einstein, he argued that Kaufmann's method and measuring results can not make a decisive judgement, relativity theory draws the simplicity into the electrodynamics of moving bodies to emancipate the puzzling electrodynamics without special hypotheses and arbitrary images. The immediate reaction to the relativity in the field of physics is, to certain extent, attributed to Plank's warm and firm support.

Empirical identity conflict underdetermines the abandonment of a theory, in same way, the stronger empirical identity underdetermines the acceptance of a theory. The strong and the weak of a theory's empirical identity are relative, that is, a theory, $T$, may show stronger empirical identity in comparison to $T_{1}$, but may show weaker empirical identity in comparison to another theory $T_{2}$; what is more, the theories are advancing, the power contract in empirical identity may change through time. The theory whose empirical identity increases rapidly in a short time is very promising and worth pursuing, but that underdetermines the acceptance of the said theory either. Scientists, at certain time, should accept a theory which has the most strong complex index, but their attitude to the theory may be changing, because, at another time (the interval of the time is generally long, because scientific research is a arduous process of expending time and energies), the condition of the theory's complex index may have changed. Any single or partial indexes, at certain moment, are factually undetermined.

\section{Funding}

This paper is supported by Chinese National Social Science Fund (11BZX031) in 2011, Chinese Education Ministry Fund for Returned Overseas Professional in 2012, and Major Guiding Fund of Southeast University in 2010.

\section{References}

Collingwood, R. G. (1956). The Idea of History. Oxford: Oxford University Press.

Feyerabend, P. (1970). Consolations for the Specialist. In Lakatos, I., \& Musgrave, A. (Eds.), Criticism and the Growth of Knowledge, Cambridge: Cambridge University Press. http://dx.doi.org/10.1017/CBO9781139171434.010

Kuhn, T. (1957). The Corpernican Pevolution: Planetary Astronomy in the Development of Western Thought. Cambridge: Harvard University Press.

Kuhn, T. (1962). The Structure of Scientific Revolution. Chicago: University of Chicago Press.

Lakatos, I. (1970). Falsification and the Methodology of Scientific Research Programmes. In Lakatos, I., \& Musgrave, A. (Eds.), Criticism and the Growth of Knowledge, Cambridge: Cambridge University Press. http://dx.doi.org/10.1017/CBO9781139171434.009

Laudan, L. (1977). Progress and Its Problems. Berkeley: University of California Press.

Ma, L. (2006). Conflict and Concert: A Fresh Study of Scientific Rationality. Beijing: The Commercial Press.

McAllister, J.W. (1996). Beauty \& Revolution in Science. Ithaca: Cornell University Press.

Popper, K. (1975). The Rationality of Scientific Revolutions. In R. Harré (Ed.), Problems of Scientific Revolution, Oxford: Oxford University Press.

\footnotetext{
${ }^{\overline{7}}$ Background thinking is one of background indices of a theory. The definition of the indicator is as follows:

By comparison between theory $T_{1}$ at time $\tau$ and theory $T_{2}$ at time $\tau^{\prime}$, we say that $T_{1}$ 's background thinking decreases (noted by $o T_{1} \tau \downarrow$ ) and $T_{2}$ 's background thinking increases (noted by $o T_{2} \tau^{\prime} \uparrow$ ), if and only if, the aggregative evaluation indicator number $m$ of $T_{1}$ 's thingking solutionors $j$ at $\tau$ (noted by $m\left(T_{1} \tau o j\right)$ ) is less than the aggregative evaluation indicator number $n$ of $T_{2}$ 's thingking solutionor $j$ at $\tau^{\prime}$ (noted by $n\left(T_{2} \tau^{\prime} o j\right)$ ). Time $\tau$ can be or can not be equal to time $\tau^{\prime}$.

The definition may be symbolized as follows:
}

$$
o T_{1} \tau \downarrow \wedge o T_{2} \tau^{\prime} \uparrow \longleftrightarrow m\left(T_{1} \tau o j\right)<n\left(T_{2} \tau^{\prime} \circ j\right)
$$

The aggregative evaluation indicators of a theory's thinking solutionors includes the number and weight of those who accept the theory, the number and weight of the problems proposed from the theory, the appraisal states of the theory, and so on. For an account of this indicator, see Ma Lei (2006), pp. 297-301. 
Scientific Research Publishing (SCIRP) is one of the largest Open Access journal publishers. It is currently publishing more than 200 open access, online, peer-reviewed journals covering a wide range of academic disciplines. SCIRP serves the worldwide academic communities and contributes to the progress and application of science with its publication.

Other selected journals from SCIRP are listed as below. Submit your manuscript to us via either submit@scirp.org or Online Submission Portal.
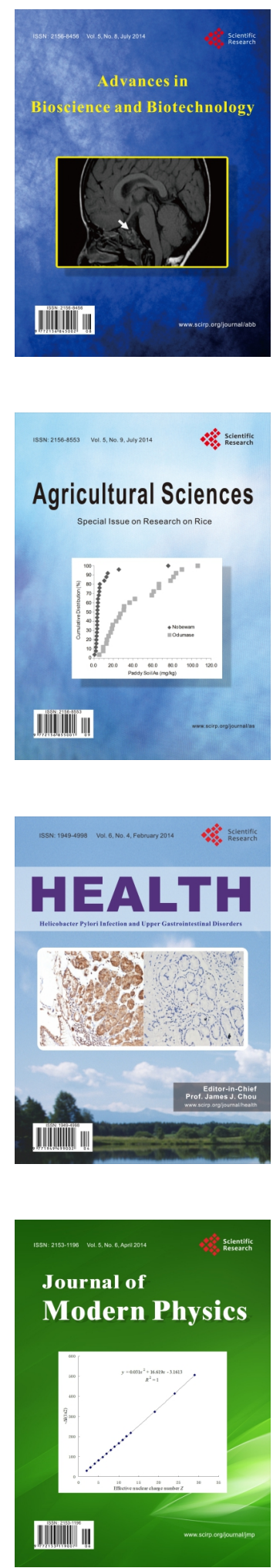
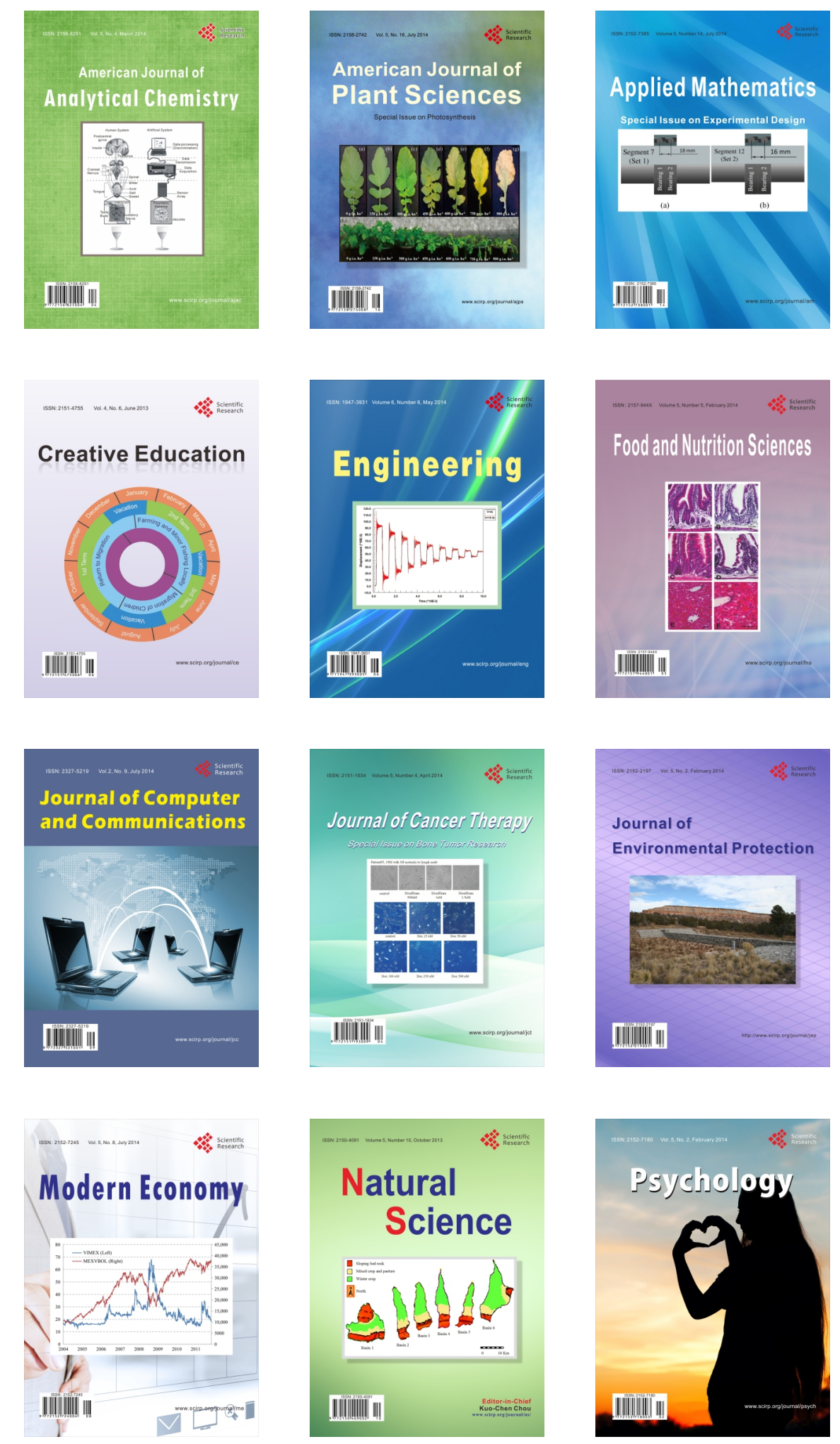